\title{
Preliminary studies on differential defense responses induced during plant communication
}

\author{
Jin Ying PENG ${ }^{1,3}$, Zhong Hai $\mathrm{LI}^{2}$, Hui XIANG ${ }^{1,3}$, Jian Hua HUANG ${ }^{1,3}$, Shi Hai JIA ${ }^{1,3}$, Xue Xia MIAO ${ }^{1}$, \\ Yong Ping $\mathrm{HUANG}^{1 *}$ \\ ${ }^{I}$ Institute of Plant Physiology and Ecology, Shanghai Institute for Biological Sciences, Graduate School of the Chinese \\ Academy of Sciences, Chinese Academy of Sciences, 300 Fenglin Road, Shanghai 200032, China \\ ${ }^{2}$ Chinese National Human Genome Center at Shanghai, 250 Bibo Road, Shanghai 201203, China \\ ${ }^{3}$ Graduate School of the Chinese Academy of Sciences, Beijing 100039, China
}

\begin{abstract}
We compared the expression patterns of three representative genes in undamaged tomato and tobacco plants in response to exposure to either tomato or tobacco fed on by Helicoverpa armigera (cotton bollworm). When tomato and tobacco, two species of one family, were incubated in the chambers with the tomato plants damaged by the cotton bollworm, the expression of the PR1, BGL2, and $P A L$ genes was up-regulated in leaves of both plants. However, the levels of gene expression were significantly higher in the tomato than that in the tobacco. In addition, the activities of enzymes, peroxidase, polyphenol oxidase, and lipoxygenase were found to be higher in the tomato than those in the tobacco. Similar results were obtained when the damaged plants were replaced by the tobacco.
\end{abstract}

Keywords: plant-plant communication, tomato (Lycopersicon esculentum), tobacco (Nicotiana tabacum), cotton bollworm (Helicoverpa armigera), inducible defenses.

\section{INTRODUCTION}

Plants are frequently damaged by herbivorous insects. Many types of defensive strategies have evolved in response to herbivore attack [1,2], including physical, mechanical and chemical defenses that deter herbivore activity $[3,4]$. Furthermore, some plants defend themselves indirectly by emitting volatile chemicals, which in turn attract the natural enemies of the herbivores $[5,6]$.

Several studies have shown that volatile chemicals are released when plants are damaged [7]. It is demonstrated that the plant defense response is not limited to the individual being damaged [8]. Damage to a plant can result in induction of chemical defenses and defense related gene expressions in neighboring plants. Plants that are exposed to volatile compounds released by damaged neighbors may increase the production of defensive chemicals even though they themselves have not been damaged $[8,9]$.

\footnotetext{
*Correspondence: Yong Ping HUANG

Tel: +86-21-54924047; Fax: +86-21-54924047;

E-mail: yongping@iris.sipp.ac.cn
}

Interestingly, in interplant communication, the receiver and emitter can be of different species [10-12]. This phenomenon suggests that healthy plants near to the damaged plants may use volatile chemicals released from damaged neighbors as cues to induce anti-herbivore defenses as a deterrent of future attack by herbivores.

Such inter-plant signal transfer has been hypothesized for over 20 years and has been a controversial topic [13, 14]. Although some studies have found no evidence for the transfer of signals between damaged and undamaged plants [15], others supported the hypothesis that chemical information was conveyed between damaged and undamaged plants $[8,9,16]$. In recent years, inter-plant communication has appeared to be better supported by more experimental evidences $[10,17]$.

Previous researches mainly concentrated on intra-specific information transfer through the volatile chemicals between plants. Oudejans and Bruin [18] extended the scope to inter-specific information transfer between cucumber and Lima bean. Since then, additional experiments were done on information transfer between inter-specific plants [10-12]. However, no reports are available about compara- 
tive study related to intra- and inter-species signaling to aerial signal emitted from damaged plants. In this study, we selected the tomato and tobacco, both of which belong to the same family, to investigate whether there exists response sensitivity difference between inter-species and intra-species information transfer.

\section{MATERIALS AND METHODS}

\section{Plant materials and insect culture}

Tomato (Lycopersicon esculentum cv Castlemart) and tobacco (Nicotiana tabacum cv Xanthinc) seeds were germinated in pots and grown for $2 \mathrm{w}$ in a growth chamber. Experiments were initiated when plants were in the late rosette stage of growth.

Cotton bollworm (Helicoverpa armigera) larvae were collected from Jiangxi province in 2003 and reared in the laboratory at $24 \pm$ $1{ }^{\circ} \mathrm{C}$, and $80 \pm 5 \%$ R.H. under a $14 \mathrm{~h}$ light $/ 10 \mathrm{~h}$ dark photoperiod. The larvae were fed on a modified semi-artificial diet as described by Li et al [19].

\section{Experimental design and sampling}

For feeding experiments, eight 4 th instar larvae that had been starved for $12 \mathrm{~h}$ were placed on each of the plant's primary leaf and allowed to feed continuously during incubation $(t=6,12 \mathrm{~h})$. Experiments were carried out in a clean, sealed container $($ diameter $=33 \mathrm{~cm}$, depth $=21 \mathrm{~cm}$ ). In one series of experiments, larvae were placed on two tomato plants; while in the second series of experiments, larvae were placed on two tobacco plants. In each replicate, two plants being fed by the cotton bollworms were positioned on one side of the container and two healthy, potted tomato and tobacco plants were placed on the other side of the container $(n=4$ uninfested and 2 infested plants per container). To prevent invasion of the uninfested plants by the cotton bollworm, we used wet cotton wool to isolate the container into an infested- and an uninfested-plant area. We used a cleaned container for each experimental replicate in order to exclude effects from the previous experiment or experimental replicate. Experiments were maintained at $25 \pm 2{ }^{\circ} \mathrm{C}, 50-70 \% \mathrm{RH}$, and $16 \mathrm{~L}-8 \mathrm{D}$ (2,150 lx fluorescent light). Uninfested tomato and tobacco plants that were kept in the same chamber with damaged tomato or tobacco plants were sampled at 6 and $12 \mathrm{~h}$ after the initiation of the experiments $(t=6,12 \mathrm{~h})$. Two uninfested potted tomato and tobacco seedlings maintained with uninfested tomato or tobacco seedlings in a container for the equal time were used as control. Cotton bollworm wounded tomato and tobacco were also sampled as the positive control. These experiments of a time course were repeated four times. Undamaged healthy plants were used in each repeat.

\section{RT-PCR analysis}

Total RNA was extracted using the cooled phenol method [28]. Total RNA pellets were dissolved in $30 \mu \mathrm{l}$ of RNase-free water and quantified by spectrophotography. RNA quality was determined by gel fractionation in agarose followed by ethidium bromide staining and UV light visualization before analysis for specific mRNAs. Reverse transcription reactions were carried out as recommended by the manufacturer (Takara, R019A, Japan). The products of reverse transcription were used as templates for PCR analysis. The primers used for PCR were designed according to the sequence reported in Genbank (Tab. 1). And the primers for $\beta$-actin gene were designed according to the conserved sequence of tomato and tobacco. To compare expression levels and minimize PCR artifacts, the number of PCR cycles was kept low [ 17 cycles for $\beta$-actin, 29 cycles for $L O X$ (lipoxygenase), 27 cycles for $B G L$ ( $\beta$-1, 3-glucanase), 22 cycles for $P A L$ (phenylalanine ammonia-lyase)], and PCR products were detected by agarose gel electrophoresis. Each experiment was repeated four times using independent samples. The PCR primers used were listed in Tab. 1.

\section{PPO, POD and LOX activity measurement}

Extracts for assays of foliar polyphenol oxidase (PPO), peroxidase (POD) and lipoxygenase (LOX) [20] were prepared by homogenizing individual, weighed leaflets in $1.25 \mathrm{ml}$ of $\mathrm{pH} 7 \mathrm{~K}$ Phos $(0.1$ M) buffer containing $7 \%$ polyvinylpolypyrrolidine. An aliquot $(0.4$ $\mathrm{ml}$ ) of a $10 \%$ solution of Triton X100 was added and the homogenate was centrifuged at $6,000 \mathrm{~g}$ for $15 \mathrm{~min}$. The resulting supernatant was used directly as an enzyme source. The activity of polyphenol oxidase and peroxidase was measured as the rate of formation of melanin-like material from phenolic substrates [20]. For the assay of polyphenol oxidase, $10-30 \mu 1$ of enzyme extract were added to $1 \mathrm{ml}$ of $2.92 \mathrm{mM}$ caffeic acid in $\mathrm{pH} 8 \mathrm{~K}$ Phos buffer $(0.1 \mathrm{M})$ and the change in absorbance of the mixture at $470 \mathrm{~nm}$ was measured for $30 \mathrm{~s}$. For assaying peroxidase activities, the procedure was identical, except that the substrate was $5 \mathrm{mM}$ guaiacol with $0.02 \mathrm{mM} \mathrm{H}_{2} \mathrm{O}_{2}$ added as a cofactor. Polyphenol oxidase and peroxidase activities were reported as $\Delta \mathrm{OD} / \mathrm{min} / \mathrm{mg}$ protein. The activity of lipoxygenase

Tab. 1 Primers used in RT-PCR analysis

\begin{tabular}{llll}
\hline Gene & Gene product & Forward primer $\left(5^{\prime} \rightarrow 3^{\prime}\right)$ & Reverse primer $\left(5^{\prime} \rightarrow 3^{\prime}\right)$ \\
\hline Tomato $P R-1$ & Pathogenesis-related protein & ATCTCATTGTTACTCACTTGTC & AACGAGCCCGACCA \\
Tomato $B G L 2$ & $\beta$-1,3-glucanase & CACCAACATTCACATAACAGAGGC & CAGGGCTGATTTCATTACCAAC \\
Tomato $P A L$ & Phe-ammonia lyase & TTCAAGGCTACTCTGGC & CAAGCCATTGTGGAGAT \\
Tomato $L O X$ & Lipoxygenase & TTTCTG CGACTTGAGGTTCGG & ATTAGTCTTTACCTTCTTGTCCAGT \\
Tobacco $P R-1$ & Pathogenesis-related protein & CTCGGTTCGTGTTGGATGT & TCGCAAGTAGCTAGACCATCA \\
Tobacco $B G L 2$ & $\beta$-1,3-glucanase & GCACAGTCTATTGGAGTATGCTATG & GGT ATT CGC TAA GAC CCC TGA \\
Tobacco $P A L$ & Phe-ammonia lyase & CCTACAAGGCTACTCTGG & AGCCGCCTTCACATA \\
Tobacco $L O X$ & Lipoxygenase & GAGCCATTCGTGATCGCAAC & GCGATTAGGGAGATAACCAGCA \\
Actin & House-keeping gene & GGGGAGGTAGTGACAATAAATAACAAA & GACTGTGAAACTGCGAATGGC \\
\hline
\end{tabular}


was measured using the formation of conjugated dienes from linoleic acid [21]. The reaction mixture consisted of 15-20 $\mu 1$ enzyme extract and $2.9 \mathrm{ml}$ of $0.4 \mathrm{mM}$ linoleic acid dispersed in $\mathrm{pH} 7 \mathrm{~K}$ Phos buffer containing $0.1 \%$ Tween 20 . Rate of change in absorbance of this mixture was measured at $234 \mathrm{~nm}$ for $10 \mathrm{~min}$. Each experiment was repeated four times using independent samples. Protein concentrations were determined using Bradford method [22].

\section{Statistics}

Statistical analysis was performed by the Student's $t$ test. The data shown here was represented as mean $\pm \mathrm{SD}$. Values of $P<0.05$ were considered as significance.

\section{RESULTS}

\section{Expression of defense-related genes induced by plants} incubated with caterpillar-damaged plants

In leaves of tomato and tobacco plants exposed to $H$. armigera-infested plants, we detected transcripts of $B G L$ ( $\beta$-1, 3-glucanase, pathogenesis-related (PR) proteins) and phenylalanine ammonia-lyase (PAL, an enzyme involved in the phenylpropanoid pathway) genes. And transcript of $L O X$ (a key enzyme of the octadecanoid pathway) gene was undetectable or weak in both treatments (Fig. 1). In the control experiments where uninfested tomato and tobacco plants were incubated with other uninfested tomato or tobacco plants, we did not detect transcripts of these

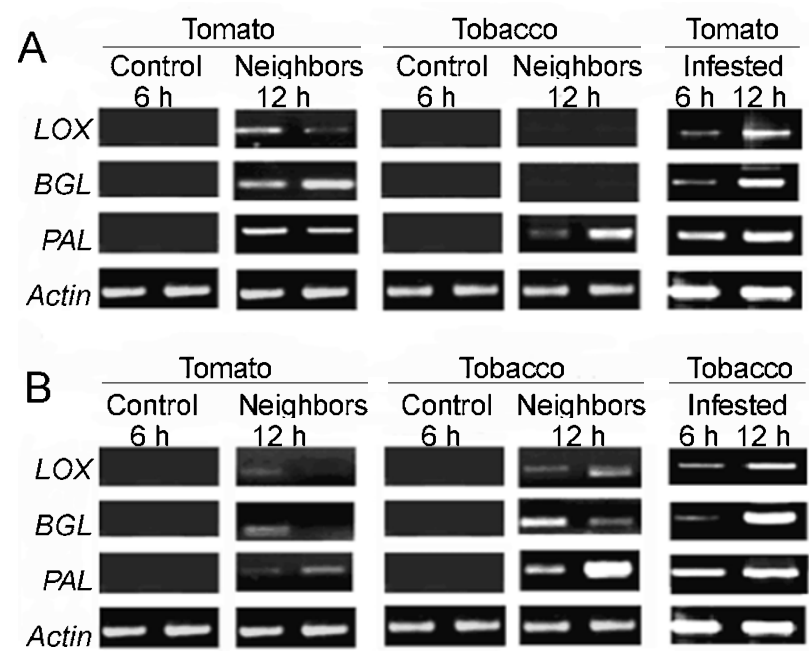

Fig. 1 Intensity of gene expression in tomato and tobacco plants exposed to grazed plants of the same and different species fed on by H. armigera. Data from intact plants exposed to grazed (A) tomato or (B) tobacco plants for 6 and $12 \mathrm{~h}$. Total RNA was isolated from the leaves of the plants and the expression of $L O X, B G L$ (basic PR2 ), and $P A L$ genes was analyzed using RT-PCR. Control experiments were carried out following the same procedure but without insect feeding. Infested tomato or tobacco was shown as a positive control. These experiments of a time course were repeated four times on independent samples. three genes (Fig. 1). Consistent with a previous study [23], transcription of $B G L$ and $P A L$ in undamaged plants was induced by exposure to the infested plants and any volatile compounds they released. As a positive control, in the infested tomato or tobacco plants, the transcripts of these three genes were all strongly up-regulated (Fig. 1 "infested").

Gene-expression patterns were compared between the two species. In the damaged tomato treatment, adjacent undamaged tomato seedlings showed a significantly stronger expression of $B G L$ and $P A L$ than undamaged tobacco (Fig. 1A). In contrast, in the infested-tobacco treatment, neighboring tomato seedlings showed a significantly weaker expression of $B G L$ and $P A L$ than the tobacco seedlings (Fig. 1B). These experiments of a time course were repeated four times on independent samples, with similar results each time, and only representative result was shown here.

\section{Plant enzyme activity assays}

After an exposure to grazed plants for $12 \mathrm{~h}, \mathrm{PPO}, \mathrm{LOX}$, and POD activities of leaves were measured. As shown in Fig. 2 and Tab. 2, after incubation with infested tomato, PPO activity of adjacent, undamaged tomato increased by 2.0-fold compared with the control tomato while PPO activity of the undamaged tobacco increased by 1.5 -fold compared with the control tobacco (two-sample $t$ test, $t_{4}$ $=2.447, P<0.05$ ). When incubated with damaged tomato plants, the activity of POD in undamaged tomato seedlings increased by 2.7-fold and of LOX in undamaged tomato seedlings by 1.8-fold, whereas the activity of POD and LOX in the tobacco seedlings was 1.7- and 1.5-fold, respectively (two-sample $t$-test, for POD, $t_{4}=2.318, P<$ 0.05 ; for LOX, $t_{4}=2.777, P>0.05$ ).

In contrast, incubation with damaged tobacco seedlings significantly increased the activity of PPO and POD in the undamaged tobacco plants as compared with that in undamaged tomato plants (Fig. 2, Tab. 2). Activity increased by 2.2 - and 2.4-fold in the tobacco whereas it was 1.3 and 1.8-fold in the tomato plants (two-sample $t$ test, PPO, $t_{4}=2.777, P<0.01$; POD $\left.t_{4}=2.776, P<0.05\right)$. However, LOX activity in the neighboring tobacco plants did not differ significantly from that of tomato (two-sample $t$ test, $P>0.05$, non-significant).

\section{DISCUSSION}

The three oxidative enzymes, PPO, POD and LOX, investigated in this study were demonstrated to play an important role in anti-herbivore defense [24]. PPO is an oxidative enzyme that is induced by actual herbivory or by exogenous application of methyl jasmonate. It has been found to be a reliable indicator of other systemic induced responses in solanaceous plants, including tobacco [24- 
A

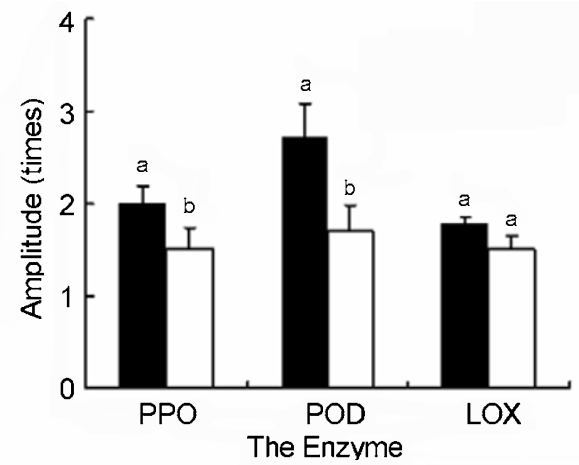

B

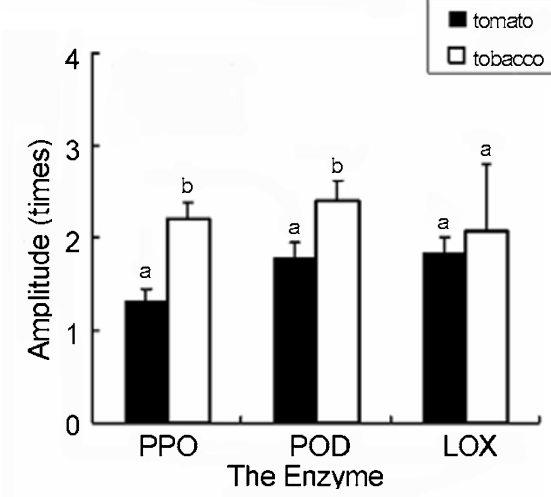

Fig. 2 Enzyme activity in neighboring tomato and tobacco seedlings after $12 \mathrm{~h}$ incubation with grazed $(\mathbf{A})$ tomato or $(\mathbf{B})$ tobacco plants. Amplitude $=\mathrm{EA}_{\text {treatment }} / \mathrm{EA}_{\text {control }}, \mathrm{EA}$ : the enzyme activity. The data are shown as mean \pm standard deviation, $n=4$. Bars with the different letters are significantly different within treatment ( $t$ test, $P<0.05)$. $\mathrm{PPO}=$ polyphenol oxidase; $\mathrm{POD}=$ peroxygenase; $\mathrm{LOX}=$ lipoxygenase.

25]. LOX is the key enzyme for the synthesis of JA and it catalyzes the production of JA from linolenic acid, which stimulates the expression of defense-related genes serving as secondary signals activating a subset of defense genes [26]. Increasing activities of these enzymes is considered as one measure of the activation of defense response.

We found that intact plants responded to some volatile cue in the presence of $H$. armigera -infested intra- and inter-specific plants. Transcripts of $B G L$ and $P A L$ were detected in both tomato and tobacco, suggesting that the neighboring tomato or tobacco can respond to grazinginduced volatiles through the activation of defensive genes. However, the intensity of the expression of three defense genes, $L O X, B G L$ and $P A L$ varied, with weak increase in the expression of the LOX pathway in either neighboring tomato or tobacco. Weak response in $L O X$ is surprising in terms of its role in jasmonic acid pathway. Probably it responds only to direct damage as opposed to volatiles, and may also be related to weak gene expression at the gene level (Fig. 1).

The sensitivity of the responses differed between species. The response to damaged plants of the same species was significantly higher than the response to damaged plants of the second species tested (Fig. 1). After incubation with infested tomato, PPO activity in neighboring undamaged tomato plants increased significantly than adjacent undamaged tobacco plants $(P<0.05)$. Similar results were observed in tobacco plants $(P<0.05)$. Different intra- and inter-specific responses may be related to different reception and succedent signal transduction mechanisms in the two species tested. The same expression pattern was found in the activity of the prooxidant enzyme POD. It was reported that POD activity increases with insect attack or leaf tissue damage [27]. Such an increase is possibly due to a direct role of POD in plant resistance mechanisms.

Since the whole plants were confined in the sealed container for 6-12 h, available $\mathrm{CO}_{2}$ may have been depleted,

Tab. 2 Enzyme activities ${ }^{\mathrm{a}}$ (mean $\pm \mathrm{SD}, n=4$ ) in seedlings exposed to the infested plants for $12 \mathrm{~h}$.

\begin{tabular}{|c|c|c|c|c|c|c|}
\hline \multirow[t]{2}{*}{ Treatment } & \multicolumn{2}{|l|}{$\mathrm{PPO}^{\mathrm{b}}$} & \multicolumn{2}{|l|}{ POD $^{b}$} & \multicolumn{2}{|l|}{ LOX $^{\mathrm{c}}$} \\
\hline & Tomato & Tobacco & Tomato & Tobacco & Tomato & Tobacco \\
\hline Control $^{1}$ & $17.9 \pm 2.7$ & $17.2 \pm 0.7$ & $16.5 \pm 1.9$ & $18.9 \pm 2.7$ & $6.3 \pm 0.3$ & $6.4 \pm 1.1$ \\
\hline Treated $^{1}$ & $35.6 \pm 2.6$ & $26.1 \pm 4.3$ & $44.9 \pm 2.7$ & $32.9 \pm 0.6$ & $11.2 \pm 0.2$ & $9.7 \pm 0.9$ \\
\hline Control $^{2}$ & $15.5 \pm 0.3$ & $15.3 \pm 3.5$ & $14.2 \pm 2.3$ & $15.3 \pm 3.5$ & $6.2 \pm 0.5$ & $7.0 \pm 0.9$ \\
\hline Treated $^{2}$ & $20.4 \pm 2.3$ & $33.8 \pm 3.5$ & $25.5 \pm 5.9$ & $36.8 \pm 4.8$ & $11.5 \pm 1.7$ & $14.5 \pm 3.2$ \\
\hline
\end{tabular}

${ }^{a}$ : Enzyme activities in units of $\Delta \mathrm{OD} / \mathrm{min} / \mathrm{mg}$ (protein concentration). $\mathrm{PPO}\left(\Delta \mathrm{E} 490 \mathrm{~min}^{-1} \mathrm{mg}^{-1}\right.$ protein), POD ( $\triangle \mathrm{E} 470 \mathrm{~min}^{-1} \mathrm{mg}^{-1}$ protein), LOX ( $\Delta \mathrm{E} 234 \mathrm{~min}^{-1} \mathrm{mg}^{-1}$ protein).

${ }^{b}$ : Assays for PPO and POD measured the rate of formation of melanin-like material from substrates.

c: Assays for LOX assay measured the formation of conjugated dienes from linoleic acid.

${ }^{1}$ : exposure to grazed (treated) and ungrazed (control) tomato seedlings

${ }^{2}$ : exposure to grazed (treated) and ungrazed (control) tobacco seedlings 
thus stressing the plants during incubation. However, Arimura and his coworkers reported that photosynthetic activity of plants in a similar sealed environment was not affected [23], suggesting that the plants were not stressed. Therefore, it seems likely that the transcriptional responses in the tomato and tobacco shown in the present study were not due to $\mathrm{CO}_{2}$ depletion.

Our results suggest that plant defensive responses are species specific. In an analysis of the effects of volatile compounds on the induction of plant defensive systems, Arimura et al [16] reported that three volatile compounds released by green leaves of lima bean species $((Z)-3$ hexenol, (E)-2-hexenal, and (Z)-3-hexenyl acetate) elicited the expression of defensive genes, but the patterns of gene expression differed for each compound. This indicated that the lima bean could distinguish among different signals. In different plant species receiving the same chemical signals, different signaling pathway may be activated, resulting in the transcription of different genes and in differing levels of enzyme activity. Evolutionarily, every plant may develop a specific response system for defense. Different species of plants have probably also evolved differing levels of alarm/defense responses. However, details of these mechanisms, and their ecological importance, remain elusive.

In conclusion, our study on the defensive responses of tomato and tobacco plants has revealed differences in the sensitivity of the response in the levels of gene expression and enzyme activity in plants exposed to damaged conspecific as compared with damaged plants of a different species in the same plant family. However, whether this phenomenon has an ecological role in the field or it extends to more distantly related plants remains an open question.

\section{ACKNOWLEDGEMENTS}

The authors sincerely thank Dr. SC LEVINGS and Prof. Xiangxiong ZHU for their comments on earlier drafts of this manuscript. This research was surported by grants from the Knowledge Innovation Program of the Chinese Academy of Sciences to Yongping HUANG as "Hundreds talent young scientists" and Key project for defense against invasive species (KSCX1-SW-13-02-01) as well as project item (01JC14051) from Science and Technology Committee of Shanghai Municipality.

Received, Nov 29, 2004

Revised, Jan 6, 2005

Accepted, Feb 3, 2005

\section{REFERENCES}

1 Karban R, Myers JH. Induced plant responses to herbivory. Annu Rev Ecol System 1989; 20:331-48.
2 Sabelis MW, Janssen A, Kant MR. Ecology: the enemy of my enemy is my ally. Science 2001; 291:2104-5.

3 Karban R, Baldwin IT. Induced Responses to Herbivory. Chicago. The University of Chicago Press, 1997.

4 Strauss SY, Agrawal AA. The ecology and evolution of plant tolerance to herbivory. Trends Ecol Evol 1999; 14:179-85.

5 Kessler A, Baldwin, IT. Defensive function of herbivore-induced plant volatile emissions in nature. Science 2001; 291:2141-4.

6 Shulaev V, Silverman P, Raskin I. Airborne signaling by methyl salicylate in plant pathogen resistance. Nature 1997; 385:718-21.

7 Arimura G., Ozawa R, Shimoda T, et al. Herbivory induced volatiles elicit defense genes in lima bean leaves. Nature 2000; 406:512-5.

8 Dolch R, Tscharntke T. Defoliation of alders (Alnus glutinosa) affects herbivory by leaf beetles on undamaged neighbors. Oecologia 2000; 125:504-11.

9 Dicke M, Bruin J. Chemical information transfer between damaged and undamaged plants. Biochem Syst Ecol 2001; 29:979-80.

10 Karban R, Baldwin IT, Baxter KJ, Laue G, Felton GW. Communication between plants: induced resistance in wild tobacco plants following clipping of neighboring sagebrush. Oecologia 2000; 125:66-71.

11 Karban R. Communication between sagebrush and wild tobacco in the field. Biochem Syst Ecol 2001; 29:995-1005.

12 Karban R, Maron J. The fitness consequences of interspecific eavesdropping between plants. Ecology 2002; 83:1209-13.

13 Baldwin IT, Schultz JC. Rapid changes in tree leaf chemistry induced by damage: evidence for communication between plants. Science 1983; 221:277-9.

14 Fowler SV, Lawton JH. Rapidly induced defenses and talking trees: the devil's advocate position. The American Naturalist 1985; 126:81-95.

15 Preston CA, Lewandowski C, Enyedi AJ, et al. Tobacco mosaic virus inoculation inhibits wound-induced jasmonic acid-mediated responses within but not between plants. Planta 1999; 209: 87-95.

16 Arimura G, Tashiro K, Kuhara S, et al. Gene responses in bean leaves induced by herbivory and by herbivore-induced volatiles. Biochem Biophys Res Commun 2000; 277:305-10.

17 Guerrieri E, Poppy GM, Powell W, Rao R, Pennacchio F. Plantto-plant communication mediating in-flight orientation of Aphidius ervi, J Chem Ecol 2002; 28:1703-15.

18 Oudejans AMC, Bruin J. Does spider-mite damage induce information transfer between plants of different species? Med Fac Landbouww Univ Gent 1995; 59:733-39.

19 Li WG., Li YP, He YG.. A modified wheat germ diet for rearing five species of cotton lepidopteran insect pests. Contr Shanghai Inst Entomol 1991; 10:35-40.

20 Duffey SS, Stout MJ. Antinutritive and toxic compounds of plant defense against insects. Arch Insect Biochem Physiol 1996; 32:3-37.

21 Hildebrand DF, Hymowitz T. Two soybean genotypes lacking lipoxygenase1. Journal of the American Oil Chemistry Society, 1981; 58:583-86.

22 Bradford MM. A rapid and sensitive method for the quantitation of microgram quantities of protein utilizing the principle of pro tein-dye binding. Anal Biochem 1976; 72:248-54.

23 Arimura G., Ozawa R, Horiuchic JI, Nishioka T, Takabayashi J. Plant-plant interactions mediated by volatiles emitted from plants 
infested by spider mites. Biochem Syst Ecol 2001; 29:1049-61.

24 Constabel CP, Ryan CA. A survey of wound- and methyl jasmonate-induced leaf polyphenol oxidase in crop plants. Phytochemistry $1998 ; 47: 507-11$.

25 Constabel CP, Bergey DR, Ryan CA. Systemin activates synthesis of wound-inducible tomato leaf polyphenol oxidase via the octadecanoid defense signaling pathway. Proc Natl Acad Sci USA 1995; 92:407-11.
26 Farmer EE, Ryan CA. Octadecanoid precursors of jasmonic acid activate the synthesis of wound-inducible proteinase inhibitors. Plant Cell 1992; 4:129-34.

27 Thaler JS. Jasmonate-inducible plant defenses cause increased parasitism of herbivore. Nature 1999; 399:686-8.

28 Sambrook J, Fritsch EF, Maniatis T. Molecular Cloning: A Laboratory Manual, 2th Eds. New York: Cold Spring Harbor Laboratory Press: Cold Spring Harbor, 1989. 